\title{
Tendências recentes da agricultura familiar no Brasil e o paradoxo da pluriatividade
}

\author{
Recent trends of family farming in Brazil and the pluriactivity paradox \\ Carlos Alves do Nascimento ${ }^{1}$ (D), Joacir Rufino de Aquino² (B), Mauro Eduardo Delgrossi3i, (i)
}

'Instituto de Economia e Relações Internacionais, Programa de Pós-graduação em Economia, Universidade Federal de Uberlândia (UFU), Uberlândia (MG), Brasil. E-mail: carlos.nascimento@ufu.br

2Departamento de Economia, Universidade do Estado do Rio Grande do Norte (UERN), Assú (RN), Brasil.

E-mail: joaciraquino@yahoo.com.br

${ }^{3}$ Faculdade UnB Planaltina, Programa de Pós-graduação em Agronegócios (PROPAGA), Universidade de Brasília (UnB), Brasília (DF), Brasil. E-mail: delgrossi@unb.br

${ }^{4}$ Faculdade UnB Planaltina, Programa de Pós-graduação em Gestão Pública (PPGPE), Universidade de Brasília (UnB), Brasília (DF), Brasil

Como citar: Nascimento, C. A., Aquino, J. R., \& Delgrossi, M. E. (2022). Tendências recentes da agricultura familiar no Brasil e o paradoxo da pluriatividade. Revista de Economia e Sociologia Rural, 60(3), e240128. https://doi. org/10.1590/1806-9479.2021.240128

Resumo: Os resultados do Censo Agropecuário 2017, divulgados no final de 2019 pelo IBGE, abriram os debates acerca das características e dos motivos da redução absoluta do contingente de agricultores familiares no Brasil vis-à-vis os números apresentados em 2006. Isso posto, o objetivo do presente artigo é se inserir nessa discussão e contribuir com a mesma a partir da utilização dos microdados da Pesquisa Nacional por Amostra de Domicílios - PNAD (de 2006 a 2015) para avaliar a evolução do número de produtores pertencentes à agricultura familiar no país. Os resultados da pesquisa revelaram que a pluriatividade se tornou, em virtude da aplicação dos critérios da Lei da Agricultura Familiar de 2006, um elemento potencial de impedimento de uma parte expressiva das famílias de contas próprias serem classificadas como agricultura familiar, o que contribui para a sua retração nas estatísticas oficiais. Por sua vez, ao lado da agricultura familiar que comercializa parte de sua produção, o trabalho mostra que uma parcela crescente da categoria se dedica a atividades produtivas para o próprio consumo, exigindo políticas públicas de inclusão produtiva e de desenvolvimento rural.

Palavras-chave: agricultura familiar, autoconsumo, pluriatividade, famílias rurais.

\begin{abstract}
The results of the 2017 Agricultural Census, released at the end of 2019 by IBGE, opened the debates about the characteristics and reasons for the absolute reduction of the contingent of family farmers in Brazil vis-à-vis the figures presented in 2006. That said, this article aims to be part of this discussion and to contribute to it from the use of microdata from the National Household Sample Survey - PNAD (from 2006 to 2015) to assess the evolution of the number of producers belonging to family farming in the country. The results of the research revealed that pluriactivity has become, due to the application of the updated criteria of the Family Agriculture Law of 2006, a potential element to prevent a significant part of self-employed families from being classified as family farmers, which contributes to reducing the number of this segment of farmers in official statistics. In turn, alongside family farming that sells part of its production, the work shows that a growing portion of the category is dedicated to productive activities for its consumption, requiring public policies for productive inclusion and rural development.
\end{abstract}

Keywords: family farming, self-consumption, pluriactivity, rural families.

\section{Introdução}

A partir da criação do Programa Nacional de Fortalecimento da Agricultura Familiar (Pronaf), em 1996, a agricultura familiarfoi eleita como a base socia/sobre a qual se pretendia implementar um novo modelo de desenvolvimento rural no Brasil. Contudo, o Pronaf, na sua origem, não tinha a ambição de atender todos os segmentos de agricultores familiares existentes no país, deixando de lado os estabelecimentos classificados como periféricos (Carneiro, 1997), mas, 
posteriormente, passou a incorporar parcelas crescentes desse segmento. Não obstante, mesmo para esse e também para os segmentos que inicialmente eram o seu público-alvo (os agricultores familiares em transição e os consolidados), o programa não tem sido bem-sucedido em atingir a todos, cobrindo apenas uma fração insuficiente deles (Aquino \& Schneider, 2015; Belik, 2015; Wanderley, 2017).

O sucesso parcial da política agrícola voltada para a agricultura familiar, devido aos aspectos mencionados, tem resultado na permanência e agravamento da desigualdade produtiva entre os próprios agricultores familiares (Aquino et al., 2018). Desse modo, a pretensa base socia/de um novo modelo de desenvolvimento rural para o Brasil segue sendo reproduzida de forma cindida entre famílias de agricultores "viáveis" - no sentido de terem maiores possibilidades de acesso aos mercados para seus produtos, assim como também maior integração às cadeias produtivas dos complexos agroindustriais - e famílias de agricultores "inviáveis" - do ponto de vista da precariedade de suas estruturas produtivas e dificuldade de produzir para o mercado, configurando-se, em uma expressiva parte dos casos, em agricultores familiares com produção restrita ao consumo próprio da família, com eventual excedente destinado ao mercado'.

Orientando-se em certa medida por essa distinção, o presente estudo procurou focar sua análise na diferenciação, dentro da agricultura familiar nacional, entre agricultores familiares com produção comercial - sem, no entanto, distinguir os que têm melhores e piores estruturas produtivas - e agricultores familiares com produção voltada para o consumo próprio (autoconsumo), conforme ficará mais claro na seção de resultados.

Dentro desse recorte, ganham relevo as observações que também serão feitas sobre a pluriatividade das famílias de trabalhadores por conta própria (divididas entre agricultores familiares e agricultores não familiares). A pluriatividade é vista na literatura especializada como uma espécie de baluarte para a agricultura familiar ao elevar a renda média domiciliar, evitando o êxodo rural, entre outras virtudes (Campanhola \& Graziano da Silva, 2000; Graziano da Silva, 1999, 2001; Schneider, 2003), especialmente para aqueles segmentos mais desestruturados (descapitalizados, com dificuldade de integração aos circuitos mercantis e produtivos, com pouco acesso a inovações tecnológicas etc.). Assim, o reconhecimento e o incentivo à pluriatividade poderiam representar uma importante alternativa de reprodução para milhões de produtores familiares agropecuários que povoam e estruturam as áreas rurais do país².

Entretanto, paradoxalmente, a pluriatividade (tradicional e, mais notadamente, intersetorial) ${ }^{3}$ tem funcionado não somente como um fator positivo, mas também contribuído para a desclassificação de expressiva parcela das famílias de trabalhadores por conta própria da condição do que é legalmente considerado por "agricultura familiar". Essa discussão entre pesquisadores da área foi desencadeada pela divulgação, no final de 2019, dos dados definitivos do Censo Agropecuário 2017, os quais sugerem - comparando com os resultados do Censo Agropecuário 2006 - uma diminuição de 9,5\% dos estabelecimentos familiares, de 4,3 para 3,9 milhões de unidades (DelGrossi, 2019; Graziano, 2019; Nery, 2019).

Nesse contexto, o objetivo central deste artigo consiste em contribuir com a discussão atual acerca do possível efeito dos critérios de classificação da agricultura familiar - estabelecidos pela Lei da Agricultura Familiar e o decreto que a regulamenta -, na enumeração (e evolução)

\footnotetext{
${ }^{1}$ A respeito da perene precariedade das estruturas produtivas de parte considerável da agricultura familiar nacional, ver, entre outros: Delgado (2005), Alves \& Rocha (2010) e Leporati et al. (2014).

2 A ideia básica é a de que através da pluriatividade a unidade produtiva familiar teria acesso a outras fontes de renda - além da renda da atividade agropecuária do próprio estabelecimento - e, portanto, elevaria a renda média familiar, além de que as rendas daquelas outras fontes (não agropecuárias ou assalariamento agropecuário em outro estabelecimento) poderiam ajudar a complementar o financiamento da própria atividade agropecuária do estabelecimento familiar.

${ }^{3}$ Ver essas definições na seção 3 dedicada à Metodologia.
} 
do contingente desse segmento social de produtores rurais. Adicionalmente, pretende-se explorar os efeitos das rendas advindas da pluriatividade para inclusão ou exclusão das famílias de contas próprias na condição de agricultores familiares, bem como verificar a composição dos distintos tipos de famílias que formam a categoria segundo a finalidade de sua produção (comercial e autoconsumo).

Duas hipóteses sustentam a argumentação desenvolvida ao longo do texto. A primeira delas é que há no campo brasileiro uma tendência à diversificação ocupacional da agricultura familiar, com uma parcela crescente do segmento dedicada a atividades para o próprio consumo (DelGrossi, 2017; Escher et al., 2014; Grisa et al., 2014). Isso porque a exigência por modernização das estruturas produtivas agropecuárias, entre outras causas, tem levado à redução das diferentes formas de ocupação nas atividades agropecuárias (Balsadi et al., 2019) e, também, à queda do número de unidades agropecuárias familiares (particularmente, famílias de agricultores por conta própria). Por outro lado, proliferam ocupações de residentes rurais em atividades não agropecuárias, que, combinado com a primeira tendência, ano a ano podem estar convertendo a agricultura familiar cada vez mais em famílias pluriativas (intersetoriais) ou em famílias exclusivamente não agropecuárias.

Já a segunda hipótese refere-se à criação e atualização da Lei no 11.326/2006, conhecida como a Lei da Agricultura Familiar, que estabeleceu critérios de classificação para que as famílias (predominantemente de contas próprias) pudessem ser definidas como agricultura familiar. Um desses critérios exige que o estabelecimento familiar seja capaz de gerar renda no mínimo igual às rendas que eventualmente possam ser geradas fora do estabelecimento por algum integrante da família. Pode-se, portanto, inferir que essa exigência impõe um limite para as famílias de contas próprias pluriativas permanecerem sendo consideradas agricultura familiar, uma vez que vários estudos demonstram a tendência das rendas não agropecuárias, em sua grande maioria, fora do estabelecimento rural familiar, serem mais elevadas do que as rendas agropecuárias dentro do estabelecimento familiar (Aquino \& Nascimento, 2020; Laurenti et al., 2015; Nascimento, 2009). A implicação disso é que a pluriatividade, como já mencionado anteriormente, passa a se tornar - em virtude da aplicação da referida lei - um elemento potencial de impedimento de uma parte das famílias de contas próprias pluriativas ser definida como agricultura familiar nas estatísticas oficiais, excluindo a sua participação das políticas de fortalecimento do setor (crédito, mercados institucionais etc.).

Para alcançar os objetivos propostos, a base de dados que optamos por utilizar não foi o Censo Agropecuário, mas os microdados da Pesquisa Nacional por Amostra de Domicílios PNAD (IBGE), os quais, diferentemente do Censo Agropecuário, permitem, por serem dados anuais, uma análise da evolução da agricultura familiar mais detalhada. A partir, portanto, dos microdados e de um conjunto de variáveis das PNADs, procuramos nos aproximar de uma classificação/definição - orientada pelos critérios da Lei no 11.326/2006 - do que pode ser considerado como agricultura familiar e, além disso, investigar a sua trajetória tendencial ao longo do período pós-lei até o último ano da PNAD disponibilizado pelo IBGE.

A estrutura do artigo está organizada em mais quatro seções, além desta Introdução. A segunda seção apresenta sucintamente a evolução histórica dos diferentes momentos de reconhecimento e definição oficial da agricultura familiar enquanto um segmento social importante para o desenvolvimento rural, até a promulgação da lei em 2006 e do decreto em 2017 que a regulamentou. Na terceira seção, expomos a metodologia utilizada para o trabalho de reprocessamento dos microdados da PNAD/IBGE a partir de variáveis específicas, a qual fundamentou a pesquisa empírica, cujos resultados se encontram na quarta seção. A quinta 
seção, por seu turno, contém as considerações finais sintetizando o resultado geral do estudo e apontando possíveis temas para futuras pesquisas.

\section{Agricultura familiar no Brasil: trajetória e mudanças na classificação oficial}

A política governamental brasileira de modernização da agricultura nas décadas de 1960, 1970 e 1980, cujo objetivo principal consistia na construção de uma maior diversidade de complexos agroindustriais ${ }^{4}$, privilegiou a grande propriedade como centro do modelo agrícola a ser estruturado no país. Como resultado dessa opção política e estratégia econômica, foram excluídos do seu raio de cobertura milhares de pequenos produtores familiares ${ }^{5}$, que formavam o segmento social produtivo mais numeroso e desfavorecido do meio rural brasileiro.

É importante frisar que até meados dos anos 1980 os estudiosos da área tratavam esse segmento por "pequena produção" ou "agricultura de subsistência", talvez muito influenciados pela legislação então vigente, o Estatuto da Terra. Contudo, no final daquela década e início da seguinte, uma série de estudos surgiu procurando demonstrar que na categoria "pequena produção" existiam tipos de produtores diferenciados e que exigiam tratamento mais refinado, destacando-se a contribuição de Kageyama \& Bergamasco (1989/1990) com os dados do Censo Agropecuário 1980.

Um dos trabalhos que também se tornaram referência nas discussões sobre a agricultura familiar foi a tese de doutorado de Ricardo Abramovay (Abramovay, 1992), seguido por um intenso debate e proposições entre diversos autores, tais como Lamarche (1993), especialmente após a publicação dos resultados do Censo Agropecuário 1985.

Já na esfera legislativa, a regulamentação do princípio constitucional a respeito da Previdência Social, com a Lei n 8.231 de 1991, trouxe uma novidade com a criação do "segurado especial" para aqueles que trabalhavam em regime de economia familiar, abrindo as portas para o reconhecimento formal da agricultura familiar. Na esteira das lutas pela valorização dessa categoria, o reconhecimento oficial da sua importância social e econômica veio com o Programa Nacional de Fortalecimento da Agricultura Familiar (Pronaf), criado em $1996^{6}$.

Outra pesquisa marcante à época foi a mensuração da agricultura familiar realizada no Censo Agropecuário 1995/1996, conhecida como a metodologia FAO/Incra, coordenada por Carlos Guanziroli (Guanziroli \& Cardim, 2000). Essa metodologia quantificou a agricultura familiar, mostrando sua relevância e papel na produção de alimentos, o que forneceu as bases para o desenho de várias políticas públicas voltadas para fomentar o seu desenvolvimento, sendo o Pronaf a primeira delas.

Com embasamento teórico crescente e a presença das políticas públicas voltadas para esse segmento, ocorreu uma grande expansão de estudos sobre as mais variadas vertentes da agricultura familiar. Dentre estes, para fins deste texto, vale destacar as pesquisas sobre pluriatividade, como os trabalhos pioneiros de Seyferth (1987), Schneider (2003), Sacco dos Anjos (1995), Carneiro (1998), Graziano da Silva (1999) e Nascimento (2008).

Não obstante as evidências apontadas sobre a importância da pluriatividade para a diversificação das fontes de renda da população do campo, esta não foi considerada no

\footnotetext{
${ }^{4}$ Os Complexos Agroindustriais (CAls) podem ser entendidos, resumidamente, como cadeias produtivas que integram, às diversas atividades agropecuárias, diferentes formas de capitais (indústrias de insumos para a agropecuária, agroindústrias processadoras, serviços diversos, além das instâncias de financiamento de todas essas atividades). Para uma discussão sobre o tema, ver, entre outros: Graziano da Silva (1998) e Delgado (2012).

${ }^{5}$ A respeito da história de exclusão decorrente do modelo agrícola adotado no país desde a colonização até a modernização produtiva pós-1960, ver, por exemplo: Delgado (2005) e Wanderley (2014).

${ }^{6}$ Decreto n 1.946, de 28 de junho de 1996 (Brasil, 1996).
} 
reconhecimento oficial da agricultura familiar em 2006, com a Lei $n^{\circ} 11.326^{7}$, que definiu como agricultor familiar aquele produtor que:

I - não detenha, a qualquer título, área maior do que 4 (quatro) módulos fiscais;

II - utilize predominantemente mão de obra da própria família nas atividades econômicas do seu estabelecimento ou empreendimento;

III - tenha renda familiar predominantemente originada de atividades econômicas vinculadas ao próprio estabelecimento ou empreendimento;

IV - dirija seu estabelecimento ou empreendimento com sua família.

Apesar dos seus limites, a Lei n 11.326 permitiu a primeira enumeração oficial da agricultura familiar no Censo Agropecuário 2006, mostrando a relevância deste público no setor agropecuário (França et al., 2009). Além disso, ela ainda estabeleceu critérios para inclusão de silvicultores, aquicultores, extrativistas, pescadores, povos indígenas e remanescentes de comunidades quilombolas entre os agricultores familiares, mas todos também estão sujeitos às mesmas quatro condições dos critérios acima.

Uma década depois, em 2017, a mesma foi regulamentada, por meio do Decreto no $9.064^{8}$, que manteve os quatro critérios de definição do agricultor familiar adotadas na versão de 2006, embora com alterações nos itens II e III, conforme a descrição a seguir:

Art. $3^{\circ}$ A UFPA [Unidade Familiar de Produção Agrária] e o empreendimento familiar rural deverão atender aos seguintes requisitos:

I - possuir, a qualquer título, área de até quatro módulos fiscais;

II - utilizar, no mínimo, metade da força de trabalho familiar no processo produtivo e de geração de renda;

III - auferir, no mínimo, metade da renda familiar de atividades econômicas do seu estabelecimento ou empreendimento; e

IV - ser a gestão do estabelecimento ou do empreendimento estritamente familiar.

Observe-se que no Decreto n’ 9.064 (Brasil, 2017), novamente, a pluriatividade das famílias rurais não foi considerada adequadamente, uma vez que sua reprodução social continuou sendo vinculada às atividades econômicas agrícolas desenvolvidas no estabelecimento. Isso terá implicações no enquadramento dos distintos segmentos de agricultores nas classificações oficiais.

De fato, fruto de um novo esforço para a delimitação da agricultura familiar no Censo Agropecuário 2017, constatou-se em estudo recente que um expressivo grupo de produtores foi desclassificado da categoria agricultura familiar devido à pluriatividade, ou seja, pela

7 Lei no 11.326, de 24 de julho de 2006 (Brasil, 2006).

8 Decreto n॰ 9.064, de 31 de maio de 2017 (Brasil, 2017). 
importância das rendas fora da unidade de produção obtidas pelos integrantes das suas famílias (DelGrossi et al., 2019).

Logo, torna-se importante investigar os efeitos das rendas oriundas da pluriatividade para inclusão ou exclusão dos produtores rurais na categoria "agricultura familiar". Igualmente, é relevante avançar na tipificação do segmento, buscando captar suas características internas no sentido de orientar novos estudos sobre o tema e subsidiar a implementação e aprimoramento das políticas públicas de desenvolvimento rural. É a essa tarefa que serão dedicadas às próximas seções.

\section{Metodologia}

\subsection{Rendas dentro e fora do estabelecimento rural}

Como o objetivo basilar deste trabalho consiste em expor os resultados empíricos de um estudo sobre as tendências da agricultura familiar após a implementação da Lei da Agricultura Familiar de 2006, contribuindo com o debate acerca dessa questão, foram necessários inicialmente dois cuidados essenciais em relação às rendas auferidas pelos membros das unidades familiares, quais sejam:

1) As rendas de assalariamento na agropecuária, dos membros das famílias da agricultura familiar (majoritariamente famílias de contas próprias) foram consideradas como rendas obtidas fora do estabelecimento; e

2) Observou-se que uma parcela significativa de unidades familiares de trabalhadores rurais por conta própria ocupa-se, além das atividades agropecuárias, também em atividades não agropecuárias. A base de dados para o presente estudo - a Pesquisa Nacional por Amostra de Domicílios (PNAD/IBGE) - não permite saber onde essas atividades (não agropecuárias) são exatamente exercidas, se no rural ou no urbano. Porém, a PNAD possibilita saber se tais atividades foram ou não exercidas dentro do estabelecimento rural. Identificamos que em torno de $15,0 \%$ das pessoas das famílias rurais de contas próprias que se ocupavam em atividades não agropecuárias exerciam essas atividades "no domicílio em que moravam" (código 3 da variável v9054). Portanto, por serem de famílias rurais executando esse tipo de atividade no próprio domicílio, nesse caso consideramos que as rendas dessas atividades foram obtidas dentro do estabelecimento. Para os demais $85,0 \%$ dos casos, consideramos as respectivas rendas como auferidas fora do estabelecimento 9 .

\subsection{Tipos de famílias "extensas" 10}

Concluída a fase anterior, foram construídos tipos de famílias que atendem (e outros que não atendem) os Critérios da Lei da Agricultura Familiar (n 11.326/2006) regulamentada pelo Decreto $n^{\circ} 9.064$ de 2017 (Brasil, 2017). Infelizmente, a PNAD não tem a informação acerca de quem administra as atividades do estabelecimento rural, de modo que os quatro tipos de famílias adotados foram definidos com base apenas nos Critérios I, II e III (tamanho da

9 Grande parte desses 85,0\% de casos, por exemplo, exercia suas atividades em "loja, oficina, fábrica, escritório, escola, repartição pública, galpão etc." (código 1 da v9054), tornando razoável supor que certamente não configuram atividades dentro do estabelecimento familiar rural agropecuário, a despeito de alguns desses tipos de estabelecimentos (loja, oficina, ...) poderem se encontrar ou não em área rural (o que, nesse caso, não é possível identificar pela PNAD).

${ }^{10}$ A definição da família extensa, seguindo a metodologia do projeto Rurbano utilizada por Campanhola \& Graziano da Silva (2000), deixa de fora da contagem os pensionistas, os empregados domésticos e os parentes dos empregados domésticos. Com isso, nossa unidade de análise constitui as famílias extensas, que compreendem, além da família nuclear, os parentes desta que vivem no mesmo domicílio (não obstante formem outro casal) e os agregados. 
propriedade, força de trabalho e renda) ${ }^{11}$, conforme referido na seção precedente. A descrição de cada um deles encontra-se no Quadro 1, apresentado a seguir.

Quadro 1. Descrição da metodologia de tipificação das famílias rurais no Brasil

\begin{tabular}{|c|c|}
\hline TIPO DE FAMÍLIA & CRITÉRIOS DE CLASSIFICAÇÃO \\
\hline Empregadora - Não familiar & $\begin{array}{l}\text { Este é o grupo/tipo de família que tem algum empregador } \\
\text { na família e que contrata qualquer número de empregados } \\
\text { (1 ou mais) e que, além disso, ou tem seu estabelecimento } \\
\text { rural com mais de } 4 \text { módulos fiscais ou, o mesmo tendo até } \\
4 \text { módulos fiscais, não atende pelo menos um dos outros } \\
\text { dois Critérios (II, III) da lei } 2006 \text { e decreto } 2017 \text {, conforme } \\
\text { mencionado acima. Portanto, família/estabelecimento de } \\
\text { agropecuária não familiar. }\end{array}$ \\
\hline Conta própria - Não familiar & $\begin{array}{l}\text { Esta fração do grupo de famílias de contas próprias não tem } \\
\text { nenhum empregador entre seus membros e, além disso, } \\
\text { ou tem seu estabelecimento rural com mais de } 4 \text { módulos } \\
\text { fiscais ou, o mesmo tendo até } 4 \text { módulos fiscais, não atende } \\
\text { o Critério III da lei } 2006 / \text { decreto } 2017 \text { (o Critério II, sobre a } \\
\text { força de trabalho, está atendido porque esse grupo familiar } \\
\text { não contrata força de trabalho). Este grupo de famílias, por } \\
\text { conseguinte, está excluído, pela lei } 2006 \text { e o decreto } 2017 \text {, de } \\
\text { ser agricultura familiar. }\end{array}$ \\
\hline Agricultura familiar & $\begin{array}{l}\text { Esta fração do grupo de famílias de contas próprias } \\
\text { (e de empregadores com até } 2 \text { empregados) tem seu } \\
\text { estabelecimento rural dentro do Critério I, de até } 4 \\
\text { módulos fiscais, e, além dele, atende, simultaneamente, os } \\
\text { outros dois Critérios (força de trabalho e renda, Critérios } \\
\text { II e III). Portanto, pela lei } 2006 \text { e o decreto } 2017 \text {, pode ser } \\
\text { classificado como agricultura familiar. As famílias de contas } \\
\text { próprias correspondiam, em } 2015 \text {, a mais de } 98,0 \% \text { do total } \\
\text { da agricultura familiar (o restante correspondia às famílias de } \\
\text { empregadores com até } 2 \text { empregados). } \\
\text { A agricultura familiar foi subdividida em dois grupos/tipos } \\
\text { familiares, assim denominados: i) Agricultura familiar com } \\
\text { produção comercial: parte da produção dessas famílias é } \\
\text { destinada ao mercado; ii) Agricultura familiar com produção } \\
\text { exclusivamente para o autoconsumo } \\
\text { famílias não né né nenhuma prupo de } \\
\text { ou conta própria ou como empregado, porém como empregador } \\
\text { de seus membros ocupado na produm } \\
\text { destinada para o consumo próprio dos integrantes da } \\
\text { família. }\end{array}$ \\
\hline Empregados & $\begin{array}{l}\text { Neste grupo/tipo familiar não há nenhum empregador e } \\
\text { nenhum trabalhador por conta própria, mas contém pelo } \\
\text { menos uma pessoa ocupada como empregada. Este grupo, } \\
\text { obviamente, não é da agricultura familiar. }\end{array}$ \\
\hline
\end{tabular}

Fonte: elaboração dos autores.

11 A PNAD não tem uma variável com a informação relativa à família/estabelecimento contratar ou não um administrador (o outro critério determinado pela lei de 2006). Porém, consideramos que é muito improvável que uma família de contas próprias contrate administrador. E, como as famílias de contas próprias correspondem a praticamente $98,0 \%$ do total da agricultura familiar (o restante são as famílias de empregadores com até 2 empregados), avaliamos que a falta dessa informação na PNAD (administração do empreendimento) não inviabiliza a investigação aqui proposta. Para este grupo, adotamos o critério de até 2 empregados permanentes dialogando com antiga classificação do Pronaf, que delimitava a classificação de agricultores familiares àqueles que contavam com auxílio de até 2 empregados permanentes.

12 Este grupo foi inserido para diálogo com os resultados dos Censos Agropecuários, uma vez que milhões de estabelecimentos são voltados majoritariamente à produção para o sustento da família. Em 2017, eram 2 milhões de estabelecimentos (Instituto Brasileiro de Geografia e Estatística, 2019, Tabela 6762). 
Note-se que para cada um dos quatro grupos/tipos de famílias elencados no Quadro 1, as famílias extensas foram subdivididas, segundo o ramo de atividades em que seus membros estavam envolvidos, da seguinte forma:

i) as famílias agropecuárias são aquelas em que pelo menos um de seus membros estava envolvido em atividades agropecuárias - e nenhum outro ocupado em atividades não agropecuárias - como sua ocupação principal na semana de referência da PNAD;

ii) as famílias pluriativas tradicionais são as que pelo menos um de seus membros exercia alguma atividade agropecuária como conta própria ou empregador e pelo menos um outro ocupado como assalariado na agropecuária (em outro estabelecimento); e

iii) as famílias pluriativas intersetoriais são aquelas em que pelo menos um de seus membros exercia alguma atividade agropecuária e pelo menos um outro exercia uma atividade não agropecuária.

\subsection{Método de cálculo das taxas de crescimento}

Com a finalidade de verificar a existência ou não de uma possível tendência linear na evolução do número de famílias nas tabelas que serão apresentadas no decorrer do texto, ajustou-se uma função log-linear do tempo'13:

$Y_{t}=\varphi e^{\theta t}$

Onde:

$Y_{t}=0$ valor da população para o ano $t$

$\varphi=0$ valor esperado de $Y$ quando $t=0$

$\theta=a$ taxa de crescimento anual

$e=$ a base dos logaritmos naturais

Uma vez que esse modelo é não linear, para transformá-lo em um modelo de regressão linear, aplica-se o logaritmo natural nos dois lados da expressão, obtendo-se o seguinte modelo $\log$-linear, em que $\varepsilon$ é o erro aleatório não explicado por ele:

$\ln Y_{t}=\ln \varphi+\theta t+\varepsilon$

Como resultado do método delineado, a taxa de crescimento média ao ano estimada para o período em análise, ou seja, não apenas entre dois pontos no tempo, foi igual a:

$\left[\left(\mathrm{e}^{\theta}-1\right) \times 100\right]$

Para a análise da evolução dos contingentes dos diferentes tipos familiares com algum membro ocupado em atividades agropecuárias existentes no Brasil como um todo (considerando os residentes urbanos mais os rurais), calculamos as taxas de crescimento para o período de 2006 a 2015. O ano de 2006 foi escolhido para iniciar a série por se referir à data de promulgação da Lei da Agricultura Familiar. Já o extremo oposto, 2015, por ser o último ano disponibilizado da PNAD pelo IBGE.

\footnotetext{
13 O modelo de regressão log-linear é utilizado para a determinação de taxas de crescimento ao longo do tempo e não apenas entre dois pontos extremos de uma série temporal - de modo que se evitam possíveis efeitos devidos a valores atípicos nas extremidades de uma série de tempo, que podem levar à subestimação ou superestimação da taxa de crescimento. Para maiores detalhes do uso dessa técnica estatística, com exemplos empíricos, ver: Neder (2000), Hoffmann (2000) e Gujarati (2006).
} 
Vale assinalar que o tratamento aqui adotado para classificar a agricultura familiar de acordo com os critérios da Lei n 11.326/2006 é impossível de ser realizado a partir da PNAD Contínua, que passou a vigorar a partir de 2016, uma vez que essa nova PNAD não contém a informação do tamanho da área dos estabelecimentos rurais. De qualquer modo, como será visto na sequência, os resultados obtidos com a metodologia adotada são suficientes para testar a validade das hipóteses lançadas no início da exposição.

\section{Resultados e discussão}

O meio rural brasileiro é marcado por uma grande diversidade social e uma marcante heterogeneidade socioeconômica. Na base desse processo, estão fatores associados ao meio ambiente e à evolução histórica particular de cada território. Também contribui para isso a ausência ou o viés particular das políticas desenvolvimentistas adotadas no país ao longo do tempo (Belik, 2015; Schneider, 2010). Tais aspectos vão repercutir nas tendências da agricultura familiar nacional no limiar do século XXI, conforme evidenciam os microdados das PNADs do IBGE.

Objetivando aprofundar o argumento acima, a Tabela 1 apresenta a evolução dos contingentes dos diferentes tipos de famílias que estruturam a totalidade das famílias brasileiras com algum membro ocupado em atividade agropecuária, de acordo com a posição na ocupação e o ramo de atividade. Identificaram-se mais de 4 milhões de agricultores familiares. Destacamos que entre esses tipos familiares se encontram os tipos da agricultura familiar - famílias de empregadores com até dois empregados e de contas próprias (ambos com produção comercial), e, apresentadas separadamente, as famílias ocupadas exclusivamente em atividades de autoconsumo (ou seja, sem produção voltada para o comércio), em uma aproximação, pelas PNADs/IBGE, aos critérios legais, como foi explicado na seção anterior.

Pode-se verificar, na Tabela 1, uma quase generalização de taxas negativas de crescimento dos distintos grupos familiares. Ou seja, com a exclusiva exceção das famílias da agricultura familiar dedicadas estritamente às atividades produtivas de autoconsumo, que exibiram taxa positiva de crescimento ( $4,2 \%$ a.a.), praticamente todos os demais tipos familiares contribuíram, uns mais intensamente que outros, para a redução do total geral dos contingentes de famílias sob análise - como se pode ver na última linha da citada tabela, o total geral dessas famílias experimentou redução a uma taxa média anual de $0,8 \%$, altamente significativa ${ }^{14}$ (no sentido estatístico), no período analisado (2006 a 2015).

Tabela 1. Distribuição e evolução dos contingentes dos tipos de famílias ocupadas na agropecuária: Brasil (urbano + rural), 2006 a 2015 ( $n^{\circ}$ de famílias x 1.000)

\begin{tabular}{|c|c|c|c|c|c|c|c|c|c|c|c|}
\hline \multirow{2}{*}{$\begin{array}{l}\text { LOCAL DOMICÍLIO / TIPO DE } \\
\text { FAMÍLIA }\end{array}$} & \multirow[t]{2}{*}{2006} & \multirow[t]{2}{*}{2007} & \multirow[t]{2}{*}{2008} & \multirow[t]{2}{*}{2009} & \multirow[t]{2}{*}{2011} & \multirow[t]{2}{*}{2012} & \multirow[t]{2}{*}{2013} & \multirow[t]{2}{*}{2014} & \multirow[t]{2}{*}{2015} & \multicolumn{2}{|c|}{$\begin{array}{l}\text { tx. cresc. } \\
\text { (\% a.a.) }\end{array}$} \\
\hline & & & & & & & & & & \multicolumn{2}{|c|}{2006 a $2015^{a}$} \\
\hline \multicolumn{12}{|l|}{ URBANO + RURAL } \\
\hline Empregadora & 407 & 341 & 423 & 389 & 301 & 293 & 268 & 272 & 278 & $-4,9$ & $\star \star \star$ \\
\hline Agropecuária & 165 & 146 & 177 & 156 & 122 & 122 & 114 & 104 & 119 & $-4,9$ & $\star \star \star *$ \\
\hline
\end{tabular}

(a) Estimativa do coeficiente de uma regressão log-linear contra o tempo. Nesse caso, o teste t indica a existência ou não de uma tendência nos dados. Os asteriscos (***, **, *) correspondem, respectivamente, $1 \%, 5 \%$ e $10 \%$ de significância. Fonte: Microdados da PNAD/IBGE (Instituto Brasileiro de Geografia e Estatística, 2018). Elaboração dos autores.

${ }^{14}$ O qualificativo significativo concerne ao teste estatístico feito para verificar se a evolução dos dados (número de famílias) apresenta alguma tendência, de crescimento ou de redução. Dessa forma, sempre que for usado doravante esse qualificativo (representado pelos asteriscos que acompanham algumas taxas nas tabelas) a intenção será a de mostrar que os dados apresentam uma certa tendência estatística, de modo que nos casos em que as taxas de crescimento das tabelas não estiverem acompanhadas de asteriscos significará que as mesmas não são estatisticamente significativas e, portanto, não representam nenhuma tendência - o que poderá ser traduzido, por conseguinte, como uma estabilidade na evolução dos dados. 
Tabela 1. Continuação...

\begin{tabular}{|c|c|c|c|c|c|c|c|c|c|c|c|}
\hline \multirow{3}{*}{$\begin{array}{l}\text { LOCAL DOMICÍLIO / TIPO DE } \\
\text { FAMÍLIA } \\
\text { Pluriativa }\end{array}$} & \multirow{3}{*}{$\begin{array}{l}2006 \\
243\end{array}$} & \multirow{3}{*}{$\begin{array}{l}2007 \\
195\end{array}$} & \multirow{3}{*}{$\begin{array}{l}2008 \\
246\end{array}$} & \multirow{3}{*}{$\begin{array}{l}2009 \\
233\end{array}$} & \multirow{3}{*}{$\begin{array}{l}2011 \\
179\end{array}$} & \multirow{3}{*}{$\begin{array}{l}2012 \\
171\end{array}$} & \multirow{3}{*}{$\begin{array}{l}2013 \\
155\end{array}$} & \multirow{3}{*}{$\begin{array}{l}2014 \\
168\end{array}$} & \multirow{3}{*}{$\begin{array}{l}2015 \\
159\end{array}$} & \multirow{2}{*}{\multicolumn{2}{|c|}{$\begin{array}{c}\begin{array}{c}\text { tx. cresc. } \\
(\% \text { a.a. })\end{array} \\
2006 \text { a } 2015^{a}\end{array}$}} \\
\hline & & & & & & & & & & & \\
\hline & & & & & & & & & & $-4,8$ & $\star * \star$ \\
\hline $\begin{array}{l}\text { Pluriatividade } \\
\text { tradicional }\end{array}$ & 13 & 6 & 11 & 7 & 13 & 10 & 8 & 4 & 8 & $-4,4$ & \\
\hline $\begin{array}{l}\text { Pluriatividade } \\
\text { intersetorial }\end{array}$ & 230 & 189 & 235 & 226 & 167 & 162 & 147 & 164 & 151 & $-4,9$ & $* * *$ \\
\hline $\begin{array}{l}\text { Contas próprias } \\
\text { (agr. não familiar) }\end{array}$ & 1349 & 1266 & 1270 & 1269 & 1206 & 1171 & 1179 & 1287 & 1211 & $-0,9$ & * \\
\hline Agropecuária & 41 & 45 & 37 & 26 & 40 & 37 & 48 & 42 & 45 & 1,8 & \\
\hline Pluriativa & 1307 & 1221 & 1233 & 1243 & 1166 & 1135 & 1130 & 1244 & 1166 & $-1,0$ & * \\
\hline $\begin{array}{l}\text { Pluriatividade } \\
\text { tradicional }\end{array}$ & 149 & 135 & 122 & 127 & 130 & 91 & 93 & 100 & 71 & $-6,4$ & $\star \star \star$ \\
\hline $\begin{array}{l}\text { Pluriatividade } \\
\text { intersetorial }\end{array}$ & 1158 & 1087 & 1111 & 1117 & 1036 & 1044 & 1037 & 1144 & 1095 & $-0,4$ & \\
\hline Agricultura familiar & 4261 & 4169 & 4220 & 4131 & 4285 & 4081 & 4220 & 4405 & 4173 & 0,1 & \\
\hline Com produção comercial & 3371 & 3189 & 3149 & 3106 & 3144 & 2897 & 2859 & 3000 & 2976 & $-1,3$ & $\star * *$ \\
\hline Agropecuária & 2790 & 2577 & 2596 & 2552 & 2645 & 2411 & 2376 & 2501 & 2536 & $-1,0$ & $\star \star$ \\
\hline Pluriativa & 581 & 612 & 553 & 554 & 499 & 487 & 483 & 500 & 440 & $-3,0$ & $\star * *$ \\
\hline $\begin{array}{l}\text { Pluriatividade } \\
\text { tradicional }\end{array}$ & 91 & 93 & 101 & 88 & 82 & 65 & 55 & 59 & 62 & $-6,2$ & $\star * \star$ \\
\hline $\begin{array}{l}\text { Pluriatividade } \\
\text { intersetorial }\end{array}$ & 490 & 519 & 452 & 466 & 417 & 421 & 428 & 441 & 378 & $-2,5$ & $\star \star \star *$ \\
\hline Com autoconsumo & 890 & 980 & 1071 & 1025 & 1141 & 1183 & 1361 & 1404 & 1197 & 4,2 & $\star * \star$ \\
\hline Empregados & 3862 & 3923 & 3922 & 3972 & 3604 & 3631 & 3567 & 3633 & 3473 & $-1,4$ & $* * *$ \\
\hline Agropecuária & 2324 & 2432 & 2363 & 2379 & 2153 & 2200 & 2107 & 2089 & 2118 & $-1,7$ & $\star * *$ \\
\hline Pluriativa & 1538 & 1490 & 1559 & 1593 & 1452 & 1430 & 1460 & 1544 & 1355 & $-0,9$ & * \\
\hline TOTAL & 9879 & 9699 & 9834 & 9762 & 9397 & 9176 & 9234 & 9597 & 9135 & $-0,8$ & $\star * *$ \\
\hline
\end{tabular}

(a) Estimativa do coeficiente de uma regressão log-linear contra o tempo. Nesse caso, o teste t indica a existência ou não de uma tendência nos dados. Os asteriscos (*** ** *) correspondem, respectivamente, 1\%, 5\% e 10\% de significância. Fonte: Microdados da PNAD/IBGE (Instituto Brasileiro de Geografia e Estatística, 2018). Elaboração dos autores.

Note-se, ainda na Tabela 1, que o único grupo familiar que exibiu taxa positiva e significativa de crescimento foi o grupo de famílias (da agricultura familiar) exclusivamente ocupadas em atividades destinadas a atender sua própria necessidade de consumo (4,2\% a.a.), em sintonia com os resultados verificados em outros estudos (DelGrossi, 2017).

A agricultura familiar total corresponde ao somatório da agricultura familiar de produção comercial com a agricultura familiar (exclusivamente) de autoconsumo. No caso do grupo agricultura familiar com produção comercial, importante observar que todos os seus diferentes tipos de famílias, classificadas de acordo com o ramo de atividade ${ }^{15}$, exibiram taxas negativas de crescimento. Essa constatação, combinada com a informação do parágrafo anterior, revela que, de um lado, a agricultura familiar no Brasil seguiu uma tendência de redução absoluta do seu contingente comercial, no período sob análise (2006 a 2015), e, de outro lado, apenas a agricultura familiar exclusivamente ocupada em atividades de autoconsumo (ou seja, sem rendas de atividades produtivas agropecuárias) é que seguiu uma trajetória tendencial de ampliação do seu contingente absoluto, no mesmo período.

A Tabela 2 confirma, pela ótica da participação relativa dos diferentes grupos familiares no total das famílias analisadas, o que foi observado do ponto de vista da evolução absoluta dos respectivos tipos familiares (Tabela 1 ). Isso porque a quase totalidade dos tipos familiares

${ }^{15}$ Ramo de atividade agropecuária e pluriativa (intersetoriat. atividade agropecuária + atividade não agropecuária, e a pluriatividade tradiciona). 
investigados exibiu tendência (sentido estatístico) de perda de participação relativa no total geral. E, novamente, o grupo familiar que se destacou, dessa vez com tendência de aumento de participação relativa, foi o grupo de famílias com atividades exclusivamente voltadas ao autoconsumo (a fração da agricultura familiar sem produção orientada para o comércio) crescendo a uma taxa média anual de 5,1\%, passando de 9,0\% de participação, em 2006, para 13,1\% em 2015, registrando, portanto, um ganho de participação de 4,1 pontos percentuais.

Tabela 2. Distribuição e evolução da participação relativa (\%) dos diferentes tipos de famílias no total de famílias: Brasil (urbano + rural), 2006 a 2015

\begin{tabular}{|c|c|c|c|c|c|c|c|c|c|c|c|}
\hline \multirow{2}{*}{$\begin{array}{l}\text { LOCAL DOMICÍLIO / TIPO DE } \\
\text { FAMÍLIA }\end{array}$} & \multirow[t]{2}{*}{2006} & \multirow[t]{2}{*}{2007} & \multirow[t]{2}{*}{2008} & \multirow[t]{2}{*}{2009} & \multirow[t]{2}{*}{2011} & \multirow[t]{2}{*}{2012} & \multirow[t]{2}{*}{2013} & \multirow[t]{2}{*}{2014} & \multirow[t]{2}{*}{2015} & \multicolumn{2}{|c|}{$\begin{array}{l}\text { tx. cresc. } \\
\text { (\% a.a.) }\end{array}$} \\
\hline & & & & & & & & & & \multicolumn{2}{|c|}{2006 a $2015^{a}$} \\
\hline \multicolumn{12}{|l|}{ URBANO + RURAL } \\
\hline Empregadora & 4,1 & 3,5 & 4,3 & 4,0 & 3,2 & 3,2 & 2,9 & 2,8 & 3,0 & $-4,1$ & $\star \star \star$ \\
\hline Agropecuária & 1,7 & 1,5 & 1,8 & 1,6 & 1,3 & 1,3 & 1,2 & 1,1 & 1,3 & $-4,2$ & $\star \star \star$ \\
\hline Pluriativa & 2,5 & 2,0 & 2,5 & 2,4 & 1,9 & 1,9 & 1,7 & 1,7 & 1,7 & $-4,1$ & $\star \star \star$ \\
\hline $\begin{array}{l}\text { Pluriatividade } \\
\text { tradicional }\end{array}$ & 0,1 & 0,1 & 0,1 & 0,1 & 0,1 & 0,1 & 0,1 & 0,0 & 0,1 & $-3,6$ & \\
\hline $\begin{array}{l}\text { Pluriatividade } \\
\text { intersetorial }\end{array}$ & 2,3 & 2,0 & 2,4 & 2,3 & 1,8 & 1,8 & 1,6 & 1,7 & 1,6 & $-4,1$ & $\star \star \star$ \\
\hline $\begin{array}{l}\text { Contas próprias (agr. não } \\
\text { familiar) }\end{array}$ & 13,7 & 13,1 & 12,9 & 13,0 & 12,8 & 12,8 & 12,8 & 13,4 & 13,3 & $-0,1$ & \\
\hline Agropecuária & 0,4 & 0,5 & 0,4 & 0,3 & 0,4 & 0,4 & 0,5 & 0,4 & 0,5 & 2,6 & \\
\hline Pluriativa & 13,2 & 12,6 & 12,5 & 12,7 & 12,4 & 12,4 & 12,2 & 13,0 & 12,8 & $-0,2$ & \\
\hline $\begin{array}{l}\text { Pluriatividade } \\
\text { tradicional }\end{array}$ & 1,5 & 1,4 & 1,2 & 1,3 & 1,4 & 1,0 & 1,0 & 1,0 & 0,8 & $-5,7$ & 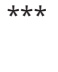 \\
\hline $\begin{array}{l}\text { Pluriatividade } \\
\text { intersetorial }\end{array}$ & 11,7 & 11,2 & 11,3 & 11,4 & 11,0 & 11,4 & 11,2 & 11,9 & 12,0 & 0,3 & \\
\hline Agricultura familiar & 43,1 & 43,0 & 42,9 & 42,3 & 45,6 & 44,5 & 45,7 & 45,9 & 45,7 & 0,9 & $\star \star \star *$ \\
\hline Com produção comercial & 34,1 & 32,9 & 32,0 & 31,8 & 33,5 & 31,6 & 31,0 & 31,3 & 32,6 & $-0,6$ & \\
\hline Agropecuária & 28,2 & 26,6 & 26,4 & 26,1 & 28,2 & 26,3 & 25,7 & 26,1 & 27,8 & $-0,2$ & \\
\hline Pluriativa & 5,9 & 6,3 & 5,6 & 5,7 & 5,3 & 5,3 & 5,2 & 5,2 & 4,8 & $-2,3$ & $* \star \star$ \\
\hline $\begin{array}{l}\text { Pluriatividade } \\
\text { tradicional }\end{array}$ & 0,9 & 1,0 & 1,0 & 0,9 & 0,9 & 0,7 & 0,6 & 0,6 & 0,7 & $-5,5$ & $\star \star \star$ \\
\hline $\begin{array}{l}\text { Pluriatividade } \\
\text { intersetorial }\end{array}$ & 5,0 & 5,4 & 4,6 & 4,8 & 4,4 & 4,6 & 4,6 & 4,6 & 4,1 & $-1,7$ & $\star \star *$ \\
\hline Com autoconsumo & 9,0 & 10,1 & 10,9 & 10,5 & 12,1 & 12,9 & 14,7 & 14,6 & 13,1 & 5,1 & $\star \star \star$ \\
\hline Empregados & 39,1 & 40,4 & 39,9 & 40,7 & 38,4 & 39,6 & 38,6 & 37,9 & 38,0 & $-0,6$ & $\star \star *$ \\
\hline Agropecuária & 23,5 & 25,1 & 24,0 & 24,4 & 22,9 & 24,0 & 22,8 & 21,8 & 23,2 & $-0,9$ & $\star \star *$ \\
\hline \multirow{2}{*}{ Pluriativa } & 15,6 & 15,4 & 15,8 & 16,3 & 15,4 & 15,6 & 15,8 & 16,1 & 14,8 & $-0,2$ & \\
\hline & 100,0 & 100,0 & 100,0 & 100,0 & 100,0 & 100,0 & 100,0 & 100,0 & 100,0 & & \\
\hline
\end{tabular}

(a) Estimativa do coeficiente de uma regressão log-linear contra o tempo. Nesse caso, o teste t indica a existência ou não de uma tendência nos dados. Os asteriscos (***,** * ) correspondem, respectivamente, 1\%, 5\% e 10\% de significância. Fonte: Microdados da PNAD/IBGE (Instituto Brasileiro de Geografia e Estatística, 2018). Elaboração dos autores.

A agricultura familiar total (comercial e autoconsumo), em virtude do desempenho das famílias com autoconsumo destacado no parágrafo anterior, ampliou a sua participação relativa (com tendência estatística de crescimento) no conjunto das famílias nacionais ocupadas na agropecuária, crescendo a uma taxa média anual altamente significativa de 0,9\% no período analisado.

O propósito da Tabela 3, por sua vez, é tão somente comparar as trajetórias dos dois grupos da agricultura familiar com a trajetória do grupo das famílias de contas próprias (agricultura não familiar). Cabe mencionar que em uma hipotética redação diferente da Lei da Agricultura Familiar e do decreto que a regulamenta, as famílias aqui classificadas como de contas próprias poderiam ser consideradas também pertencentes ao grupo da agricultura familiar. 
Nessa tabela, chama atenção o perfil inverso de ambos os grupos familiares. Ou seja, por um lado, observamos que as famílias de contas próprias são predominantemente famílias pluriativas intersetoriais (90,4\%, em 2015; e com tendência de crescimento de 0,5\% a.a.). Por outro lado, as famílias da agricultura familiar com produção comercial, contrariamente, são: i) preponderantemente famílias agropecuárias (85,2\%, em 2015), além desse tipo também exibir uma tendência de crescimento (0,3\% a.a.); e ii) suas famílias pluriativas registraram tendência de perda de participação relativa.

Tabela 3. Distribuição e evolução da participação relativa (\%) das famílias agropecuárias e pluriativas no total de cada tipo familiar: Brasil (urbano + rural), 2006 a 2015

\begin{tabular}{|c|c|c|c|c|c|c|c|c|c|c|c|}
\hline \multirow{2}{*}{$\begin{array}{l}\text { LOCAL DOMICÍLIO / TIPO DE } \\
\text { FAMÍLIA }\end{array}$} & \multirow[t]{2}{*}{2006} & \multirow[t]{2}{*}{2007} & \multirow[t]{2}{*}{2008} & \multirow[t]{2}{*}{2009} & \multirow[t]{2}{*}{2011} & \multirow[t]{2}{*}{2012} & \multirow[t]{2}{*}{2013} & \multirow[t]{2}{*}{2014} & \multirow[t]{2}{*}{2015} & \multirow{2}{*}{\multicolumn{2}{|c|}{$\begin{array}{c}\begin{array}{c}\text { tx. cresc. } \\
(\% \text { a.a. })\end{array} \\
2006 \text { a } 2015^{a}\end{array}$}} \\
\hline & & & & & & & & & & & \\
\hline \multicolumn{12}{|l|}{ URBANO + RURAL } \\
\hline Contas próprias (agr. não familiar) & 100,0 & 100,0 & 100,0 & 100,0 & 100,0 & 100,0 & 100,0 & 100,0 & 100,0 & & \\
\hline Agropecuária & 3,1 & 3,5 & 2,9 & 2,0 & 3,3 & 3,1 & 4,1 & 3,3 & 3,7 & 2,7 & \\
\hline Pluriativa & 96,9 & 96,5 & 97,1 & 98,0 & 96,7 & 96,9 & 95,9 & 96,7 & 96,3 & $-0,1$ & \\
\hline $\begin{array}{l}\text { Pluriatividade } \\
\text { tradicional }\end{array}$ & 11,1 & 10,7 & 9,6 & 10,0 & 10,8 & 7,8 & 7,9 & 7,8 & 5,9 & $-5,6$ & *** \\
\hline $\begin{array}{l}\text { Pluriatividade } \\
\text { intersetorial }\end{array}$ & 85,9 & 85,8 & 87,5 & 88,0 & 85,9 & 89,1 & 88,0 & 88,9 & 90,4 & 0,5 & $* *$ \\
\hline \multicolumn{12}{|l|}{ Agricultura familiar } \\
\hline Com produção comercial & 100,0 & 100,0 & 100,0 & 100,0 & 100,0 & 100,0 & 100,0 & 100,0 & 100,0 & & \\
\hline Agropecuária & 82,8 & 80,8 & 82,4 & 82,2 & 84,1 & 83,2 & 83,1 & 83,3 & 85,2 & 0,3 & ** \\
\hline Pluriativa & 17,2 & 19,2 & 17,6 & 17,8 & 15,9 & 16,8 & 16,9 & 16,7 & 14,8 & $-1,7$ & ** \\
\hline $\begin{array}{l}\text { Pluriatividade } \\
\text { tradicional }\end{array}$ & 2,7 & 2,9 & 3,2 & 2,8 & 2,6 & 2,3 & 1,9 & 2,0 & 2,1 & $-5,0$ & $* \star^{*}$ \\
\hline $\begin{array}{l}\text { Pluriatividade } \\
\text { intersetorial }\end{array}$ & 14,5 & 16,3 & 14,3 & 15,0 & 13,3 & 14,5 & 15,0 & 14,7 & 12,7 & $-1,2$ & \\
\hline Com autoconsumo & 100,0 & 100,0 & 100,0 & 100,0 & 100,0 & 100,0 & 100,0 & 100,0 & 100,0 & 0,0 & \\
\hline
\end{tabular}

(a) Estimativa do coeficiente de uma regressão log-linear contra o tempo. Nesse caso, o teste t indica a existência ou não de uma tendência nos dados. Os asteriscos ( $* * * * * *$ ) correspondem, respectivamente, 1\%,5\% e 10\% de significância. Fonte: Microdados da PNAD/IBGE (Instituto Brasileiro de Geografia e Estatística, 2018). Elaboração dos autores.

Esse resultado é compatível com a hipótese que apresentamos na introdução deste artigo, uma vez que uma das razões da exclusão das famílias de contas próprias da classificação como agricultura familiar foi o não atendimento do critério da Lei da Agricultura Familiar que exige a igualdade ou o predomínio das rendas agropecuárias (obtidas dentro do estabelecimento rural) sobre as rendas não agropecuárias (adquiridas fora do estabelecimento rural).

Em outras palavras, os registros da Tabela 3, no que diz respeito às famílias de contas próprias, sugerem, portanto, que a pluriatividade maior dessas famílias (fração da pluriatividade intersetorial) é que foi a responsável principal pela sua exclusão da classificação como agricultura familiar. Da mesma forma, consideramos as rendas de assalariamento agropecuário como rendas auferidas fora do estabelecimento da família, ou seja, rendas obtidas de outro estabelecimento, o que significa dizer que as famílias de contas próprias pluriativas tradicionais - que obtêm renda, em parte, do próprio estabelecimento (de atividades por conta própria de pelo menos um dos membros da família) e, de outra parte, decorrente de assalariamento de algum outro membro familiar em outra propriedade agropecuária - também têm sua cota de contribuição decorrente do peso das rendas de assalariamento obtidas fora do estabelecimento familiar para a exclusão de parte das famílias de contas próprias da classificação de agricultura familiar. No 
caso, por fim, das famílias de contas próprias agropecuárias (não familiar), certamente o motivo de exclusão se deve não só ao nível de renda, mas ao critério do tamanho do estabelecimento por ter sido superior ao limite de quatro módulos fiscais.

Com efeito, diferentemente do que foi revelado do agregado nacional (Tabela 1), do ponto de vista das macrorregiões, observa-se que a agricultura familiar total (e seus segmentos comercial e de autoconsumo) exibiu tendência estatística positiva de crescimento apenas nas regiões Norte e Sudeste, a taxas médias anuais de, respectivamente, $4,1 \%$ e 2,1\%, no período em análise (Tabela 4). Por outro lado, entre as outras três regiões, apenas no Nordeste houve o registro de aumento do grupo de famílias com produção exclusiva para o autoconsumo (6,3\% a.a.), o que se contrapôs à redução da agricultura familiar comercial nordestina, fazendo com que o total da agricultura familiar nordestina permanecesse estável (embora com taxa negativa, porém não significativa no sentido estatístico), no período em questão.

Tabela 4. Distribuição e evolução regional dos contingentes dos tipos de famílias da agricultura familiar (urbano + rural), 2006 a 2015 ( $n^{\circ}$ de famílias x 1.000)

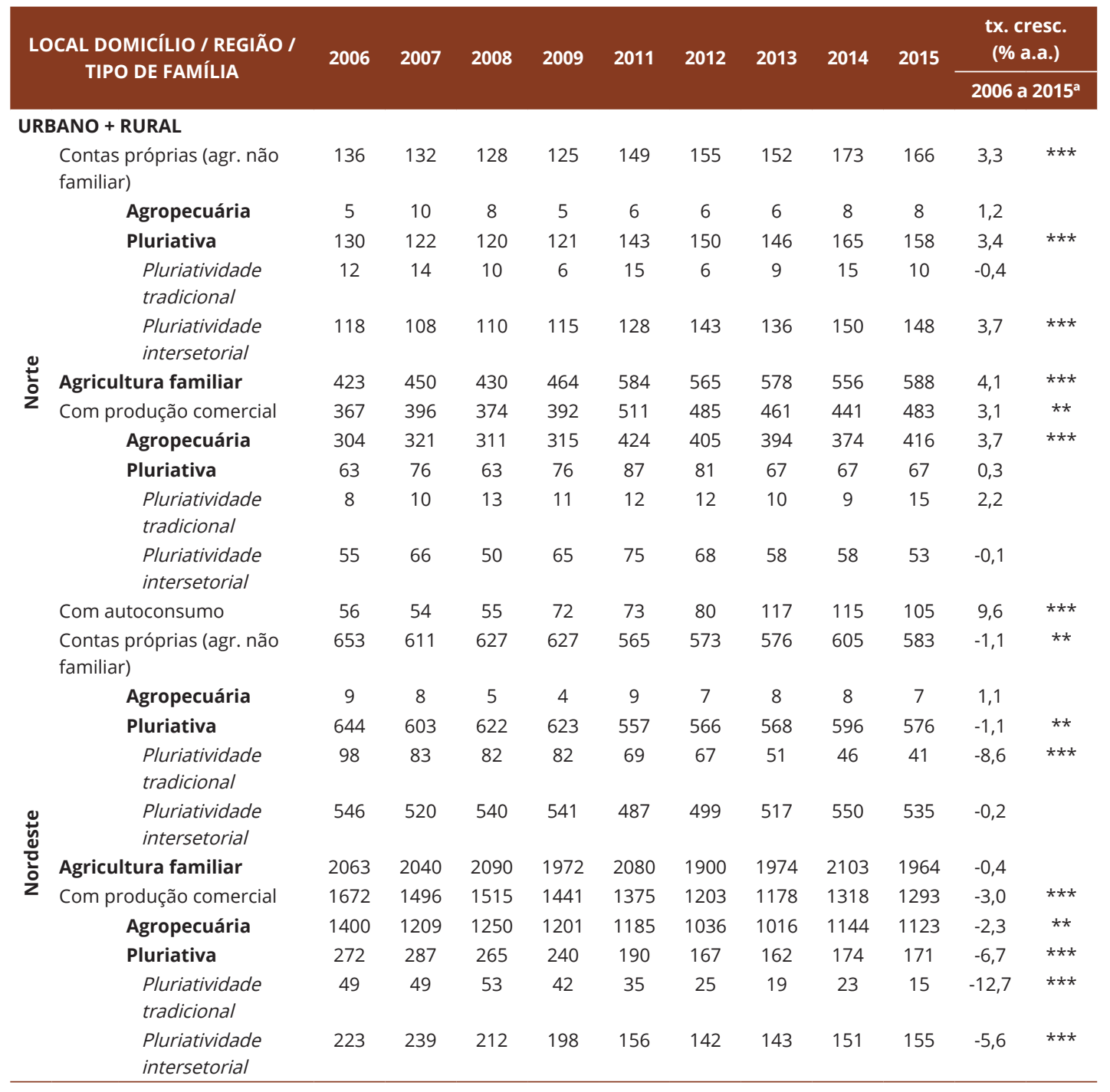

Notas: Os dois traços (--) significam os tipos de famílias com menos de 6 observações na amostra em um ou mais anos da série. (a) Estimativa do coeficiente de uma regressão log-linear contra o tempo. Nesse caso, o teste t indica a existência ou

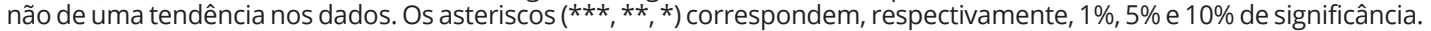
Fonte: Microdados da PNAD/IBGE (Instituto Brasileiro de Geografia e Estatística, 2018). Elaboração dos autores. 
Tabela 4. Continuação...

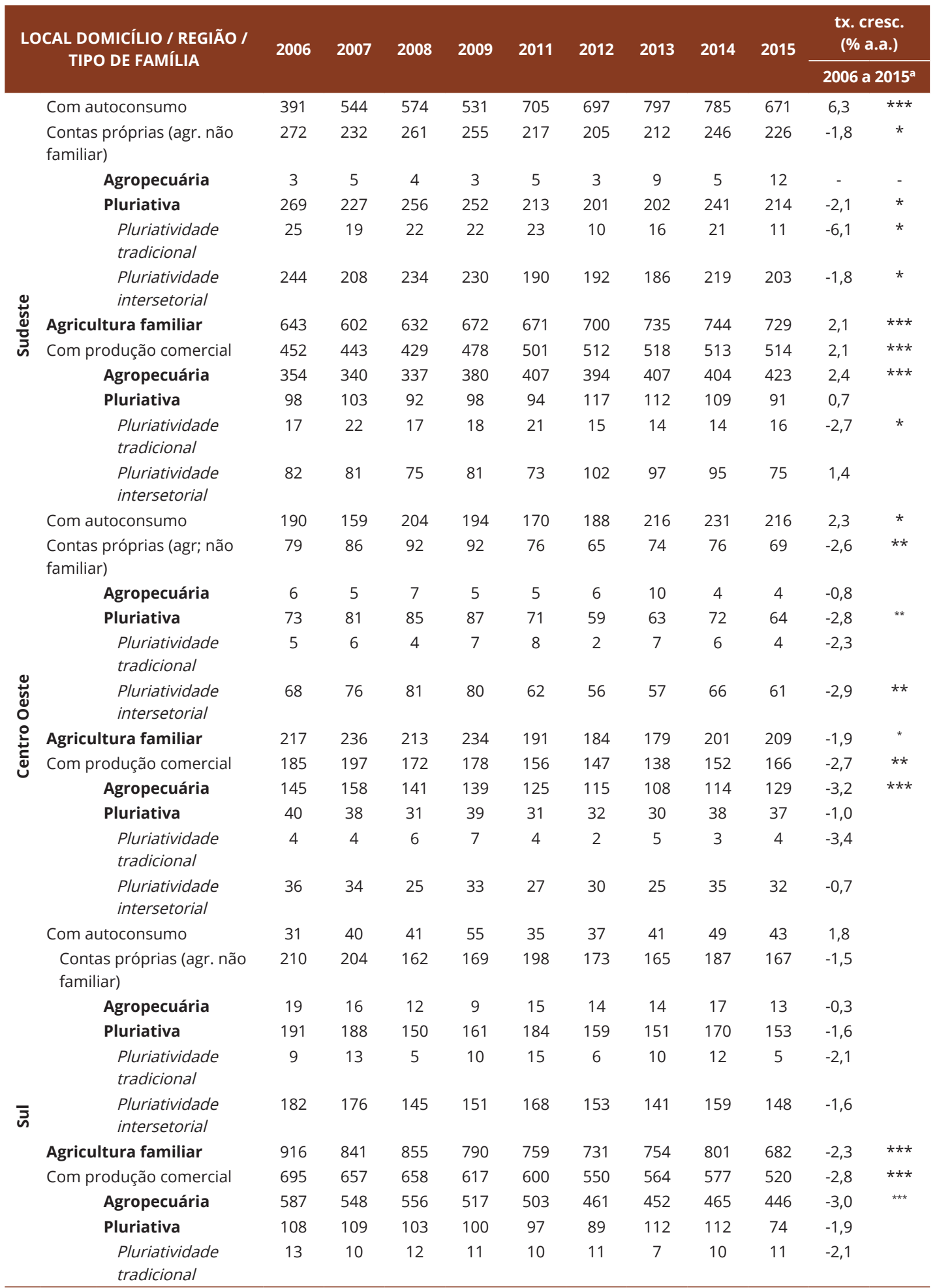

Notas: Os dois traços (--) significam os tipos de famílias com menos de 6 observações na amostra em um ou mais anos da série. (a) Estimativa do coeficiente de uma regressão log-linear contra o tempo. Nesse caso, o teste t indica a existência ou

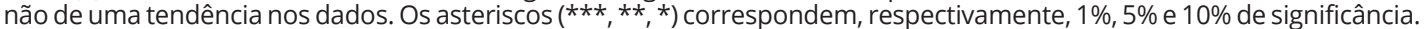
Fonte: Microdados da PNAD/IBGE (Instituto Brasileiro de Geografia e Estatística, 2018). Elaboração dos autores. 
Tabela 4. Continuação...

\begin{tabular}{|c|c|c|c|c|c|c|c|c|c|c|}
\hline \multirow{2}{*}{$\begin{array}{l}\text { LOCAL DOMICÍLIO / REGIÃO / } \\
\text { TIPO DE FAMÍLIA }\end{array}$} & \multirow[t]{2}{*}{2006} & \multirow[t]{2}{*}{2007} & \multirow[t]{2}{*}{2008} & \multirow[t]{2}{*}{2009} & \multirow[t]{2}{*}{2011} & \multirow[t]{2}{*}{2012} & \multirow[t]{2}{*}{2013} & \multirow[t]{2}{*}{2014} & \multirow[t]{2}{*}{2015} & $\begin{array}{l}\text { tx. cresc. } \\
\text { (\% a.a.) }\end{array}$ \\
\hline & & & & & & & & & & 2006 a $2015^{a}$ \\
\hline $\begin{array}{l}\text { Pluriatividade } \\
\text { intersetorial }\end{array}$ & 95 & 99 & 90 & 89 & 86 & 78 & 105 & 102 & 63 & $-1,9$ \\
\hline Com autoconsumo & 221 & 184 & 196 & 173 & 158 & 181 & 190 & 224 & 162 & $-1,0$ \\
\hline
\end{tabular}

Notas: Os dois traços (--) significam os tipos de famílias com menos de 6 observações na amostra em um ou mais anos da série. (a) Estimativa do coeficiente de uma regressão log-linear contra o tempo. Nesse caso, o teste t indica a existência ou não de uma tendência nos dados. Os asteriscos (***, **, *) correspondem, respectivamente, 1\%, 5\% e 10\% de significância. Fonte: Microdados da PNAD/IBGE (Instituto Brasileiro de Geografia e Estatística, 2018). Elaboração dos autores.

Quanto às regiões Centro-Oeste e Sul, chama atenção na Tabela 4 o fato de que apenas nessas duas regiões foram registradas, de um lado, taxas negativas de crescimento da agricultura familiar total e comercial - (1,9\% a.a. e 2,7\% a.a. e 2,3\% a.a. e 2,8\% a.a., respectivamente) - e, de outro, as famílias que produzem exclusivamente para o autoconsumo não exibiram tendência de crescimento (permaneceram estáveis, no sentido estatístico), entre 2006 e 2015.

Retornando à análise agregada nacionalmente, e circunscrevendo as observações apenas à agricultura familiar (comercial com e sem as famílias de autoconsumo), a Tabela 5 registra a distribuição e evolução da participação relativa dos contingentes de famílias desse segmento social produtivo de acordo com as faixas de tamanho dos seus respectivos estabelecimentos agropecuários e os tipos de famílias (agropecuárias e pluriativas).

É possível perceber na referida tabela que a agricultura familiar nacional total (comercial e exclusivamente para autoconsumo) está fortemente concentrada (86,2\%, em 2015) na menor faixa de área (entre 0 e 20 hectares), além de que foi unicamente nessa faixa de área que se registrou uma tendência de crescimento $(0,8 \%$ a.a.) da participação relativa do número de famílias da agricultura familiar, no período sob análise (2006 a 2015). As outras duas faixas, contrariamente, perderam participação relativa exibindo taxas negativas e significativas de crescimento.

Tabela 5. Distribuição e evolução da participação relativa (\%) dos tipos de famílias da agricultura familiar, segundo faixas de tamanho de área (em hectares): Brasil (urbano + rural), 2006 a 2015

\begin{tabular}{|c|c|c|c|c|c|c|c|c|c|c|c|}
\hline $\begin{array}{l}\text { LOCAL DOMICÍLIO / FAIXAS DE } \\
\text { ÁREA (ha) / TIPO DE FAMÍLIA }\end{array}$ & 2006 & 2007 & 2008 & 2009 & 2011 & 2012 & 2013 & 2014 & 2015 & \multicolumn{2}{|c|}{$\begin{array}{c}\text { tx. cresc. } \\
\text { (\% a.a.) } \\
2006 \text { a } 2015^{\circ}\end{array}$} \\
\hline \multicolumn{12}{|c|}{$\begin{array}{l}\text { URBANO + RURAL } \\
\text { Agricultura familiar com producão comercial mais agricultura familiar exclusivamente com autoconsumo }\end{array}$} \\
\hline [0 a 20ha] & 80,4 & 81,3 & 82,4 & 82,6 & 85,3 & 85,4 & 86,3 & \multicolumn{3}{|c|}{ Agricultura familiar com produção comercial mais agricultura familiar exclusivamente com autoconsumo } & 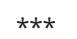 \\
\hline Agropecuária & 70,0 & 70,2 & 72,2 & 72,1 & 75,9 & 76,0 & 77,0 & 76,9 & 77,7 & 1,3 & $\star \star \star$ \\
\hline Pluriativa & 10,3 & 11,1 & 10,3 & 10,5 & 9,3 & 9,3 & 9,2 & 9,2 & 8,5 & $-2,4$ & $\star \star \star$ \\
\hline Pluriatividade tradicional & 1,6 & 1,5 & 1,8 & 1,5 & 1,4 & 1,2 & 0,9 & 1,1 & 1,1 & $-5,8$ & $\star \star \star$ \\
\hline \multicolumn{12}{|l|}{ intersetorial } \\
\hline [20 a 100ha] & 16,6 & 16,4 & 15,2 & 15,5 & 12,7 & 12,3 & 12,1 & 11,9 & 11,9 & $-4,2$ & $* \star *$ \\
\hline Agropecuária & 13,8 & 13,0 & 12,6 & 12,9 & 10,7 & 10,1 & 10,0 & 10,0 & 10,3 & $-3,9$ & $\star \star \star$ \\
\hline Pluriativa & 2,8 & 3,3 & 2,6 & 2,6 & 2,0 & 2,3 & 2,1 & 1,9 & 1,7 & $-5,9$ & $\star \star \star$ \\
\hline Pluriatividade tradicional & 0,4 & 0,6 & 0,6 & 0,5 & 0,4 & 0,4 & 0,3 & 0,2 & 0,3 & $-8,0$ & $\star \star \star$ \\
\hline \multicolumn{11}{|l|}{ intersetorial } & $\star \star \star$ \\
\hline [100ha a mais] & 3,0 & 2,4 & 2,4 & 2,0 & 2,1 & 2,3 & 1,6 & 2,0 & 1,8 & $-4,2$ & ** \\
\hline Agropecuária & 2,3 & 1,8 & 2,0 & 1,4 & 1,6 & 1,9 & 1,3 & 1,6 & 1,4 & $-4,0$ & $\star \star$ \\
\hline Pluriativa & 0,7 & 0,6 & 0,4 & 0,5 & 0,5 & 0,4 & 0,3 & 0,4 & 0,5 & $-4,5$ & * \\
\hline Pluriatividade tradicional & 0,1 & 0,1 & 0,1 & 0,1 & 0,1 & 0,0 & 0,1 & 0,0 & 0,1 & - & - \\
\hline Pluriatividade & 0,6 & 0,5 & 0,3 & 0,4 & 0,4 & 0,4 & 0,3 & 0,4 & 0,4 & $-3,9$ & \\
\hline \multicolumn{12}{|c|}{ intersetorial } \\
\hline \multicolumn{12}{|c|}{ Apenas agricultura familiar com produção comercial } \\
\hline [0 a 20ha] & $75,2^{3}$ & 75,5 & 76,5 & 76,8 & 79,9 & 79,4 & 79,8 & 79,5 & 80,7 & 0,8 & $\star \star \star$ \\
\hline
\end{tabular}


Tabela 5. Continuação...

\begin{tabular}{|c|c|c|c|c|c|c|c|c|c|c|c|}
\hline $\begin{array}{l}\text { LOCAL DOMICÍLIO / FAIXAS DE } \\
\text { ÁREA (ha) / TIPO DE FAMÍLIA }\end{array}$ & 2006 & 2007 & 2008 & 2009 & 2011 & 2012 & 2013 & 2014 & 2015 & \multicolumn{2}{|c|}{$\begin{array}{l}\text { tx. cresc. } \\
(\% \text { a.a. }) \\
2006 \text { a } 2015^{a}\end{array}$} \\
\hline Agropecuária & 62,4 & 61,4 & 62,9 & 63,2 & 67,4 & 66,4 & 66,4 & 66,3 & 68,9 & 1,2 & $\star \star \star$ \\
\hline Pluriativa & 12,8 & 14,1 & 13,6 & 13,6 & 12,5 & 13,0 & 13,3 & 13,2 & 11,8 & $-0,9$ & \\
\hline Pluriatividade tradicional & 2,0 & 2,0 & 2,3 & 2,0 & 1,9 & 1,7 & 1,3 & 1,6 & 1,5 & $-4,4$ & $\star \star \star *$ \\
\hline Pluriatividade & 10,8 & 12,1 & 11,2 & 11,7 & 10,5 & 11,3 & 12,0 & 11,6 & 10,2 & $-0,3$ & \\
\hline intersetorial & & & & & & & & & & & \\
\hline [20 a 100ha] & 21,0 & 21,4 & 20,3 & 20,6 & 17,3 & 17,4 & 17,8 & 17,5 & 16,8 & $-2,8$ & $\star \star \star *$ \\
\hline Agropecuária & 17,5 & 17,1 & 16,9 & 17,1 & 14,5 & 14,2 & 14,8 & 14,7 & 14,4 & $-2,5$ & *** \\
\hline Pluriativa & 3,5 & 4,4 & 3,5 & 3,5 & 2,8 & 3,2 & 3,1 & 2,8 & 2,4 & $-4,6$ & $\star \star * *$ \\
\hline Pluriatividade tradicional & 0,5 & 0,8 & 0,8 & 0,7 & 0,5 & 0,5 & 0,5 & 0,3 & 0,4 & $-6,7$ & ** \\
\hline Pluriatividade & 3,0 & 3,6 & 2,7 & 2,8 & 2,2 & 2,7 & 2,5 & 2,5 & 1,9 & $-4,2$ & ** \\
\hline intersetorial & & & & & & & & & & & \\
\hline [100ha a mais] & 3,8 & 3,1 & 3,2 & 2,6 & 2,8 & 3,2 & 2,4 & 3,0 & 2,6 & $-2,8$ & * \\
\hline Agropecuária & 2,9 & 2,3 & 2,7 & 1,9 & 2,2 & 2,6 & 1,9 & 2,4 & 1,9 & $-2,6$ & \\
\hline Pluriativa & 0,9 & 0,8 & 0,5 & 0,7 & 0,6 & 0,6 & 0,5 & 0,6 & 0,6 & $-3,1$ & \\
\hline Pluriatividade tradicional & 0,1 & 0,2 & 0,1 & 0,2 & 0,1 & 0,1 & 0,1 & 0,1 & 0,1 & - & - \\
\hline Pluriatividade & 0,7 & 0,6 & 0,4 & 0,6 & 0,5 & 0,6 & 0,4 & 0,5 & 0,5 & $-2,5$ & \\
\hline
\end{tabular}

Notas: Os dois traços (--) significam os tipos de famílias com menos de 6 observações na amostra em um ou mais anos da série. (a) Estimativa do coeficiente de uma regressão log-linear contra o tempo. Nesse caso, o teste t indica a existência ou não de uma tendência nos dados. Os asteriscos $(* * *, * *, *)$ correspondem, respectivamente, 1\%, 5\% e 10\% de significância. Fonte: Microdados da PNAD/IBGE (Instituto Brasileiro de Geografia e Estatística, 2018). Elaboração dos autores.

Considerando apenas a agricultura familiar comercial (sem somar com o grupo de famílias ocupadas exclusivamente com autoconsumo), a distribuição pelas faixas de tamanho de área melhorou - nesse caso, a concentração na menor faixa de área é um pouco inferior $(80,7 \%$, em 2015), comparativamente ao caso do parágrafo anterior -, embora se deva notar que também no presente caso a Tabela 5 evidencia uma tendência estatística de crescimento $(0,8 \%$ a.a.) na faixa de menor tamanho de área.

Todas as informações discutidas até aqui compreenderam os diferentes tipos de famílias, com algum membro ocupado em atividades agropecuárias residentes indiferenciadamente nas áreas urbanas e rurais do país, sejam as famílias de empregadores, as de contas próprias, as de empregados ou as famílias da agricultura familiar (comercial e de autoconsumo). Contudo, vale a pena destacar também, para uma noção comparativa, a participação, em termos relativos, de cada um desses tipos familiares que residem nas áreas exclusivamente rurais (Tabela 6) no total geral (apresentado anteriormente, especialmente na Tabela 1).

Tabela 6. Distribuição e evolução da participação relativa (\%) das famílias rurais ocupadas na agropecuária no total das famílias nacionais (rural + urbano) também ocupadas na agropecuária: Brasil, 2006 a 2015

\begin{tabular}{|c|c|c|c|c|c|c|c|c|c|c|c|}
\hline \multirow{2}{*}{$\begin{array}{l}\text { LOCAL DOMICÍLIO / TIPO DE } \\
\text { FAMÍLIA }\end{array}$} & \multirow[t]{2}{*}{2006} & \multirow[t]{2}{*}{2007} & \multirow[t]{2}{*}{2008} & \multirow[t]{2}{*}{2009} & \multirow[t]{2}{*}{2011} & \multirow[t]{2}{*}{2012} & \multirow[t]{2}{*}{2013} & \multirow[t]{2}{*}{2014} & \multirow[t]{2}{*}{2015} & \multicolumn{2}{|c|}{$\begin{array}{l}\text { tx. cresc. } \\
\text { (\% a.a.) }\end{array}$} \\
\hline & & & & & & & & & & 2006 & $2015^{a}$ \\
\hline \multicolumn{12}{|l|}{ RURAL } \\
\hline Empregadora & 34,6 & 36,8 & 41,9 & 40,2 & 41,0 & 36,8 & 35,8 & 35,4 & 36,7 & $-0,4$ & \\
\hline Agropecuária & 41,8 & 43,1 & 55,2 & 54,4 & 55,6 & 48,9 & 42,4 & 53,0 & 40,1 & $-0,3$ & \\
\hline Pluriativa & 29,7 & 32,1 & 32,4 & 30,7 & 31,1 & 28,2 & 31,0 & 24,5 & 34,2 & $-0,6$ & \\
\hline Pluriatividade tradicional & 76,8 & 66,7 & 68,9 & 79,1 & 70,1 & 37,7 & 51,1 & 70,7 & 57,5 & - & - \\
\hline Pluriatividade intersetorial & 27,1 & 31,0 & 30,6 & 29,1 & 28,1 & 27,7 & 29,9 & 23,5 & 33,0 & $-0,3$ & \\
\hline Contas próprias (agr. não familiar) & 49,1 & 49,5 & 48,4 & 47,8 & 50,4 & 52,3 & 52,1 & 53,5 & 53,6 & 1,2 & $\star \star \star *$ \\
\hline Agropecuária & 69,7 & 83,4 & 77,9 & 75,4 & 70,4 & 70,1 & 71,6 & 72,1 & 83,9 & 0,0 & \\
\hline
\end{tabular}

Notas: Os dois traços (--) significam os tipos de famílias com menos de 6 observações na amostra em um ou mais anos da série. (a) Estimativa do coeficiente de uma regressão log-linear contra o tempo. Nesse caso, o teste t indica a existência ou não de uma tendência nos dados. Os asteriscos (***, **, *) correspondem, respectivamente, 1\%, 5\% e 10\% de significância. Fonte: Microdados da PNAD/IBGE (Instituto Brasileiro de Geografia e Estatística, 2018). Elaboração dos autores. 
Tabela 6. Continuação...

\begin{tabular}{|c|c|c|c|c|c|c|c|c|c|c|c|}
\hline \multirow{2}{*}{$\begin{array}{l}\text { LOCAL DOMICÍLIO / TIPO DE } \\
\text { FAMÍLIA }\end{array}$} & \multirow[t]{2}{*}{2006} & \multirow[t]{2}{*}{2007} & \multirow[t]{2}{*}{2008} & \multirow[t]{2}{*}{2009} & \multirow[t]{2}{*}{2011} & \multirow[t]{2}{*}{2012} & \multirow[t]{2}{*}{2013} & \multirow[t]{2}{*}{2014} & \multirow[t]{2}{*}{2015} & \multicolumn{2}{|c|}{$\begin{array}{l}\text { tx. cresc. } \\
\text { (\% a.a.) }\end{array}$} \\
\hline & & & & & & & & & & \multicolumn{2}{|c|}{2006 a $2015^{a}$} \\
\hline Pluriativa & 48,4 & 48,3 & 47,5 & 47,3 & 49,8 & 51,8 & 51,2 & 52,8 & 52,5 & 1,2 & $\star \star \star$ \\
\hline Pluriatividade tradicional & 86,8 & 87,1 & 88,4 & 86,6 & 83,2 & 86,9 & 80,1 & 82,5 & 87,3 & $-0,5$ & \\
\hline Pluriatividade intersetorial & 43,5 & 43,5 & 43,0 & 42,8 & 45,6 & 48,7 & 48,6 & 50,2 & 50,2 & 2,0 & $\star \star \star$ \\
\hline Agricultura familiar & 75,4 & 76,7 & 76,1 & 75,9 & 76,2 & 77,1 & 76,2 & 74,5 & 77,3 & 0,0 & \\
\hline Com produção comercial & 80,3 & 79,9 & 79,3 & 78,7 & 78,5 & 78,8 & 77,9 & 76,9 & 78,7 & $-0,3$ & $\star \star \star *$ \\
\hline Agropecuária & 83,4 & 82,5 & 81,9 & 81,7 & 81,0 & 81,7 & 80,6 & 80,5 & 80,4 & $-0,4$ & $\star \star \star$ \\
\hline Pluriativa & 65,3 & 68,8 & 67,1 & 64,7 & 65,4 & 64,0 & 64,5 & 59,0 & 68,5 & $-0,5$ & \\
\hline Pluriatividade tradicional & 91,5 & 91,8 & 89,5 & 87,1 & 86,6 & 85,4 & 86,2 & 82,4 & 90,3 & $-0,7$ & * \\
\hline Pluriatividade intersetorial & 60,5 & 64,6 & 62,1 & 60,5 & 61,2 & 60,7 & 61,7 & 55,8 & 65,0 & $-0,2$ & \\
\hline Com autoconsumo & 56,8 & 66,2 & 66,7 & 67,4 & 69,8 & 72,9 & 72,7 & 69,2 & 73,8 & 2,1 & *** \\
\hline Empregados & 52,2 & 53,9 & 53,3 & 54,1 & 52,1 & 54,8 & 55,3 & 54,2 & 56,4 & 0,6 & ** \\
\hline Agropecuária & 64,2 & 65,4 & 65,6 & 64,7 & 60,9 & 64,0 & 63,5 & 62,5 & 63,7 & $-0,4$ & \\
\hline Pluriativa & 33,9 & 35,2 & 34,7 & 38,1 & 39,1 & 40,8 & 43,6 & 42,9 & 44,9 & 3,2 & $\star \star \star ~$ \\
\hline TOTAL & 61,0 & 62,5 & 62,0 & 61,9 & 62,5 & 63,8 & 63,9 & 62,9 & 65,0 & 0,5 & *** \\
\hline
\end{tabular}

Notas: Os dois traços (--) significam os tipos de famílias com menos de 6 observações na amostra em um ou mais anos da série. (a) Estimativa do coeficiente de uma regressão log-linear contra o tempo. Nesse caso, o teste t indica a existência ou não de uma tendência nos dados. Os asteriscos $(* * *, * *, *)$ correspondem, respectivamente, $1 \%, 5 \%$ e $10 \%$ de significância. Fonte: Microdados da PNAD/IBGE (Instituto Brásileíro de Geografia e Estatística, 2018). Elaboração dos autores.

Por esse ângulo analítico, podemos visualizar, na Tabela 6, que de todos os tipos/grupos familiares, como seria razoável esperar, são as famílias de empregadores as que têm uma fração menor de seu grupo residindo em áreas rurais - apenas 36,7\%, em 2015, e sem tendência de crescimento. Por outro lado, as famílias de contas próprias (não familiar) e as de empregados disputam a segunda maior participação (em relação ao total, urbano + rural) de seus pares residindo em áreas rurais - 53,6\% e 56,4\%, respectivamente, em 2015; ambas, porém, com tendência estatística de crescimento nessa participação. Compete ainda observar que esses três grupos familiares (empregadores, contas próprias e empregados) residem em áreas rurais em uma proporção abaixo da média nacional (65,0\%, em 2015).

Diferentemente desses três grupos familiares, as famílias da agricultura familiar se destacam por exibirem uma maior porcentagem de suas famílias residindo em áreas rurais, bem acima da média nacional. A agricultura familiar comercial, porém, não obstante fosse a que majoritariamente $(78,7 \%$, em 2015$)$ residisse no meio rural, apresentou uma tendência de redução nessa participação ( $0,3 \%$ a.a.). Enquanto isso, a fração da agricultura familiar devotada exclusivamente à produção para o autoconsumo, e que também predominantemente reside no meio rural (73,8\%, em 2015), foi a que registrou uma tendência positiva de crescimento, a uma taxa média de 2,1\% a.a. Ou seja, para uma parcela crescente do segmento estudado, o campo está passando a desempenhar cada vez mais a função de local de moradia, sendo essa uma tendência marcante para os próximos anos e que necessita ser mais bem compreendida em novas pesquisas.

\section{Considerações finais}

Os resultados do Censo Agropecuário 2017 abriram a possibilidade de um rico debate concernente aos motivos da redução absoluta do contingente de agricultores familiares nas estatísticas oficiais. Procuramos nos inserir nessa discussão e contribuir com ela a partir da utilização dos 
microdados das PNADs (de 2006 a 2015) para avaliar, entre outros tipos familiares ocupados na agropecuária, a evolução do número de produtores pertencentes à agricultura familiar.

Este artigo explorou, portanto, as PNADs como fonte de informações, procurando dialogar com as tendências apontadas pelos censos agropecuários do IBGE. Embora essas duas pesquisas utilizem unidades de investigação e metodologias diferenciadas, era esperado que ambas apontassem para tendências na mesma direção. Assim, mesmo que a PNAD tenha uma metodologia própria, distinta daquela adotada nos recenseamentos, os resultados aos quais chegamos parecem ser bastante consistentes com os resultados divulgados pelo último Censo Agropecuário/IBGE.

Primeiramente, importa ressaltar que os dados apresentados neste artigo - baseados nas PNADs - revelaram que, dentro do universo de famílias brasileiras (urbanas mais rurais) ocupadas em atividades agropecuárias, a redução numérica de famílias foi quase unânime entre os diferentes tipos de famílias investigadas (empregadoras, contas próprias, empregados e agricultura familiar), entre 2006 e 2015. Isso significa que a queda do contingente de agricultores familiares - observada pelo Censo Agropecuário 2017 e, neste artigo, pela PNAD - não é um fato exclusivo desse grupo familiar, uma vez que se insere numa dinâmica mais ampla que envolve e afeta, em termos de trajetória de decrescimento, todos os tipos de famílias estudadas, no referido período. A única exceção, contudo, foi o da fração da agricultura familiar ocupada exclusivamente com atividades agropecuárias para o autoconsumo, haja vista que esse grupo familiar, ao contrário dos demais, registrou tendência positiva de crescimento, em termos absolutos e relativos, no mesmo intervalo de tempo.

Por outro lado, diferentemente da tendência nacional dos dois grupos da agricultura familiar (comercial e autoconsumo), registramos uma clara heterogeneidade regional, na qual apenas o Nordeste se assemelha ao agregado do conjunto da nação provavelmente pelo fato de essa região abrigar quase a metade da agricultura familiar do país e, por essa razão, exercer maior influência sobre o total da categoria. As regiões Norte e Sudeste exibiram taxas positivas de crescimento dos dois grupos da agricultura familiar (comercial e autoconsumo), enquanto as regiões Centro-Oeste e Sul experimentaram tendência de redução da agricultura familiar comercial e estabilidade da agricultura familiar de autoconsumo.

Contudo, indiferenciadamente dos dados nacionais ou regionais, pudemos evidenciar e mostrar a coerência de nossas hipóteses iniciais de que as determinações da Lei da Agricultura Familiar tornaram a pluriatividade (tradicional e, sobretudo, a intersetorial) um fator potencial de exclusão (desclassificação) de parte expressiva das famílias de contas próprias da condição de agricultores familiares. Entendemos, assim, que é essa a causa subjacente à observação de que enquanto as famílias de contas próprias (agricultura não familiar, ou seja, excluída da definição de agricultura familiar) apresentaram-se majoritariamente famílias pluriativas, o grupo da agricultura familiar (comercial) revelou-se predominantemente agropecuária (não pluriativa).

Os critérios legais de classificação da agricultura familiar tornaram-na, assim, pouco pluriativa. Além disso, nota-se também a tendência de concentração crescente dos agricultores familiares em estabelecimentos agropecuários de no máximo 20 hectares de tamanho de área. Podemos, então, intuir que, de um lado, as possibilidades de produção e geração de renda desses produtores familiares estão menores em virtude de eles estarem abrigados em menores propriedades e, de outro lado, o que a pluriatividade poderia oferecer em termos de alternativas de geração de renda para essas famílias fica bloqueado legalmente. Logo, para ter acesso às políticas de crédito rural, como o Pronaf, é forçosamente impraticável para o produtor ser pluriativo. Isso porque tornar-se pluriativo pode resultar em exclusão da condição de agricultor familiar e, consequentemente, exclusão do acesso aos recursos das políticas para o setor. Esse é o dilema que está posto aos agricultores familiares do Brasil na atualidade. 
Tal fato representa um grande desafio, haja vista que devido às suas dimensões, abrangendo mais de 4 milhões de famílias, a agricultura familiar continua tendo uma relevante importância social e econômica no território nacional, cabendo às políticas públicas o amparo aos diferentes tipos de produtores agrícolas e/ou pluriativos.

Evidentemente, os achados deste artigo possuem limitações de escopo e espaço, devendo ser completados por muitos outros temas não tratados aqui, a exemplo da contribuição da agricultura familiar para a segurança alimentar e nutricional das famílias brasileiras. Por conseguinte, abrem-se muitas perspectivas para estudos futuros, tais como: verificar a importância das diferentes fontes de rendimento para os segmentos de agricultores familiares e não familiares; explorar possíveis destinos das rendas pluriativas para a produção nos estabelecimentos; aprofundar estudos regionais sobre as dinâmicas de emprego não agrícola. Ademais, também é interessante investigar as razões pelas quais a região Sudeste ultrapassou, no período estudado, a região Sul no total de agricultores familiares, bem como verificar os fatores determinantes da predominância do setor de subsistência na agropecuária nordestina e as explicações para a sua variação particular nos estados do país.

\section{Referências}

Abramovay, R. (1992). Paradigmas do capitalismo agrário em questão. São Paulo: Hucitec.

Alves, E., \& Rocha, D. P. (2010). Ganhar tempo é possível? In J. G. Gasques, J. E. Vieira Filho \& Z. Navarro (Orgs.), A agricultura brasileira: desempenho, desafios e perspectivas (pp. 275290). Brasília: IPEA.

Aquino, J. R., \& Nascimento, C. A. (2020). A Grande Seca e as fontes de ocupação e renda das famílias rurais no Nordeste do Brasil. Revista Economica do Nordeste, 51(2), 81-97.

Aquino, J. R., \& Schneider, S. (2015). O PRONAF e o desenvolvimento rural brasileiro: avanços, contradições e desafios para o futuro. In C. Grisa \& S. Schneider (Orgs.), Políticas públicas de desenvolvimento rural no Brasil(pp. 53-81). Porto Alegre: Editora da UFRGS. Recuperado em 18 de novembro, de http://www.ufrgs.br/pgdr/publicacoes/livros/outras-publicacoes/ politicas-publicas-de-desenvolvimento-rural-no-brasil

Aquino, J. R., Gazolla, M., \& Schneider, S. (2018). Dualismo no campo e desigualdades internas na agricultura familiar brasileira. Revista de Economia e Sociologia Rural, 56(1), 123-142.

Balsadi, O. V., Belik, W., \& DelGrossi, M. E. (2019). The rural of São Paulo state in perspective: evolution of agricultural and non-agricultural occupations in the 2004-2014 period. Revista da $A B E T, 18,120-140$.

Belik, W. (2015). A Heterogeneidade e suas implicações para as políticas públicas no rural brasileiro. Revista de Economia e Sociologia Rural, 53(1), 9-30.

Brasil. (1996). Decreto No 1.946, de 28 de junho de 1996. Recuperado em 10 de Janeiro de 2020, de http://www.planalto.gov.br/ccivil_03/decreto/D1946.htm.

Brasil. (2006). Lei No 11.326, de 24 de julho de 2006. Recuperado em 10 de Janeiro de 2020, de http://www.planalto.gov.br/ccivil_03/_Ato2004-2006/2006/Lei/L11326.htm.

Brasil. (2017). Decreto No9.064, de 31 de maio de 2017. Recuperado em 10 de Janeiro de 2020, de http://www.planalto.gov.br/ccivil_03/_Ato2015-2018/2017/Decreto/D9064.htm.

Campanhola, C., \& Graziano da Silva, J. (Orgs.), (2000). O novo rural brasileiro: uma análise nacional e regional. Jaguariúna: EMBRAPA. 
Carneiro, M. J. (1997). Política pública e agricultura familiar: uma leitura do PRONAF. Estudos Sociedade e Agricultura, 8, 70-82.

Carneiro, M. J. (1998). Ruralidade: novas identidades em construção. Estudos Sociedade e Agricultura, 11, 53-75.

Delgado, G. C. (2005). O setor de subsistência na economia brasileira: gênese histórica e formas de reprodução. In L. Jaccoud (Org.), Questão social e políticas sociais no Brasil contemporâneo (pp. 19-50). Brasília: IPEA.

Delgado, G. C. (2012). Do capital financeiro na agricultura à economia do agronegócio: mudanças cíclicas em meio século (1965-2012). Porto Alegre: Editora da UFRGS.

DelGrossi, M. E. (2017). A agricultura familiar e a nova ruralidade entre 2004 e 2014. In R. S. Maluf \& G. Flexor (Eds.), Questões agrárias, agrícolas e rurais: conjunturas e políticas públicas (pp. 257-268). Rio de Janeiro: E-papers Serviços Editoriais.

DelGrossi, M. E. (2019). Agricultura familiar: um caso de sucesso das políticas públicas. Jornal Correio Braziliense, Recuperado em 18 de novembro, de https://www.correiobraziliense. com.br/app/noticia/opiniao/2019/11/18/internas_opiniao,807192/artigo-agricultura-familiarum-caso-de-sucesso-das-politicas-publica.shtml

DelGrossi, M. E., Florido, A. C., Rodrigues, L.F., \& Oliveira, M. S. (2019). Comunicação de pesquisa: delimitando a agricultura familiar nos censos agropecuários brasileiros. Revista NECAT, 16, 40-45.

Escher, F., Schneider, S., Scarton, L. M., \& Conterato, M. A. (2014). Caracterização da pluriatividade e dos plurirrendimentos da agricultura brasileira a partir do Censo Agropecuário 2006. Revista de Economia e Sociologia Rural, 52(4), 643-668.

França, C. G., DelGrossi, M. E., \& Marques, V. P. M. A. (2009). O Censo Agropecuário 2006 e a agricultura familiar no Brasil. Brasília: MDA.

Graziano da Silva, J. (1998). A nova dinâmica da agricultura brasileira. Campinas, SP: UNICAMP-IE.

Graziano da Silva, J. (1999). O novo rural brasileiro (2. ed.). Campinas: UNICAMP/IE.

Graziano da Silva, J. (2001). Velhos e novos mitos do rural brasileiro. Estudos Avançados, 15(43), 37-50.

Graziano, X. (2019). Censo Agropecuário derruba narrativa da esquerda agrária. Jornal Correio da Semana, Recuperado em 30 de outubro, de https://jornalcorreiodasemana.com. br/2019/10/30/opiniao-censo-agropecuario-derruba-narrativa-da-esquerda-agraria/

Grisa, C., Schneider, S., \& Conterato, M. A. (2014). A produção para autoconsumo no Brasil: uma análise a partir do Censo Agropecuário 2006. In S. Schneider \& B. Ferreira \& F. Alves (Orgs.), Aspectos multidimensionais da agricultura brasileira: diferentes visões do Censo Agropecuário 2006 (pp. 165-186). Brasília: IPEA.

Guanziroli, C. E., \& Cardim, S. E. (2000). Novo retrato da agricultura familiar: o Brasil redescoberto. Brasília: editora.

Gujarati, D. N. (2006). Econometria básica (4. ed.). Rio de Janeiro: Ed. Campus.

Hoffmann, R. (2000). Quatro tipos de testes de hipóteses com os dados das PNADs. In C. Campanhola \& J. Graziano da Silva (Orgs.), O novo rural brasileiro: uma análise nacional e regional (pp. 137-155). Jaguariúna: EMBRAPA.

Instituto Brasileiro de Geografia e Estatística - IBGE. (2018). Microdados da Pesquisa Nacional por Amostra de Domicilios (PNAD). Recuperado em 20 de Janeiro de 2020, de https:// www.ibge.gov.br/estatisticas/sociais/trabalho/19897-sintese-de-indicadores-pnad2. html?=\&t=microdados. 
Instituto Brasileiro de Geografia e Estatística - IBGE/SIDRA. (2019). Censo Agropecuário 2017: resultados definitivos. Rio de Janeiro: IBGE. Recuperado em 20 de Janeiro de 2020, de <https://sidra.ibge.gov.br/pesquisa/censo-agropecuario/censo-agropecuario-2017>.

Kageyama, A. A., \& Bergamasco, S. M. P. P. (1989/1990). A estrutura da produção no campo em 1980. Perspectivas, 12(13), 55-72.

Lamarche, H. (Coord.), (1993). A agricultura familiar: comparação internacional(Vol. 1). Campinas: Editora da UNICAMP.

Laurenti, A. C., Pellini, T., \& Telles, T. S. (2015). Evolução da ocupação e do rendimento das pessoas no espaço rural brasileiro no período de 2001 a 2009. Revista de Economia e Sociologia Rural, 53(2), 321-342.

Leporati, M., Salcedo, S., Jara, B., Boero, V., \& Muñoz, M. (2014). La agricultura familiar em cifras. In: S. Salcedo, \& L. Gusmán (Eds.), Agricultura familiar en América Latina y el Caribe (pp. 35-56). Santiago/Chile: FAO.

Nascimento, C. A. (2008). Pluriatividade, pobreza rural e políticas públicas: uma análise comparada entre Brasil e União Europeia. Fortaleza: BNB. (BNB Teses e Dissertações; n. 11).

Nascimento, C. A. (2009). A pluriatividade das famílias rurais no Nordeste e no Sul do Brasil: pobreza rural e políticas públicas. Economia e Sociedade, 18(2), 317-348.

Neder, H. D. (2000). A Utilização estatística das informações das PNADs: testes de hipóteses e reamostragem. In: C. Campanhola, \& J. Graziano da Silva (Orgs.), O novo rural brasileiro: uma análise nacional e regional (pp. 101-136). Jaguariúna: EMBRAPA.

Nery, C. (2019). Em onze anos, agricultura familiar perde 9,5\% dos estabelecimentos e 2,2 milhões de postos de trabalho. Rio de Janeiro: IBGE. Recuperado em 25 de outubro, de https://agenciadenoticias.ibge.gov.br/agencia-noticias/2012-agencia-de-noticias/ noticias/25786-em-onze-anos-agricultura-familiar-perde-9-5-dos-estabelecimentos-e-22-milhoes-de-postos-de-trabalho

Sacco dos Anjos, F. (1995). A agricultura familiar em transformação: o caso dos colonos-operários de Massaranduba (Santa Catarina). Pelotas: Editora da UFPEL.

Schneider, S. (2003). Pluriatividade na agricultura familiar. Porto Alegre: Editora da UFRGS.

Schneider, S. (2010). Reflexões sobre diversidade e diversificação: agricultura, formas familiares e desenvolvimento rural. Ruris: Revista do Centro de Estudos Rurais, 4(1), 85-131.

Seyferth, G. (1987). Aspectos da proletarização do campesinato no Vale do Itajaí (SC): os colonosoperários. In J. S. L. Lopes (Coord.), Cultura \& identidade operária: aspectos da cultura da classe trabalhadora (pp. 103-120). Rio de Janeiro: UFRJ; São Paulo: PROED.

Wanderley, M. N. B. (2014). O campesinato brasileiro: uma história de resistência. Revista de Economia e Sociologia Rural, 52(1), 25-44.

Wanderley, M. N. B. (2017). "Franja periférica", "pobres do campo", "camponeses": dilemas da inclusão social dos pequenos agricultores familiares. In G. C. Delgado \& S. M. P. P. Bergamasco (Orgs.), Agricultura familiar brasileira: desafios e perspectivas de futuro (pp. 64-81). Brasília: SEAF. 